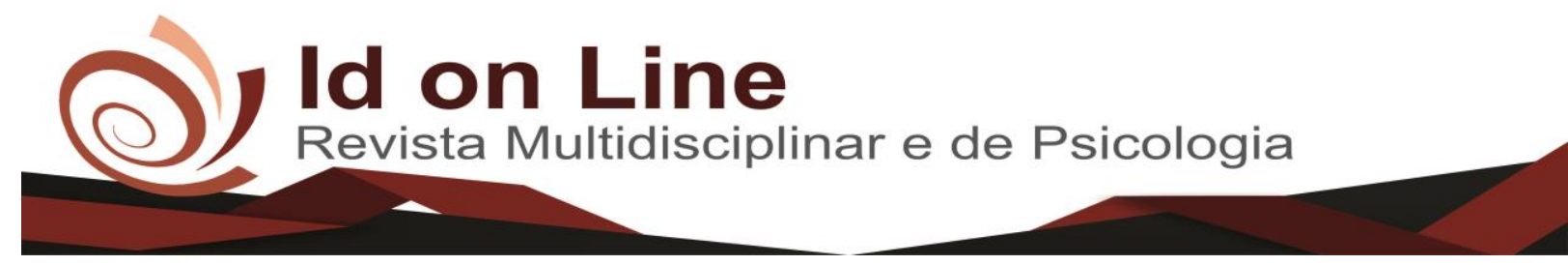

Artigo

\title{
A Literatura na Educação Infantil: A Formação de Leitores em uma Escola de Educação Infantil no Distrito de Cariutaba - Farias Brito - CE
}

\author{
Emanuel Mateus da Silva
}

\begin{abstract}
Resumo: A leitura tem sido uma questão que tem constituído uma grande preocupação não somente para a escola, mas também para toda a sociedade. Trabalhar a leitura desde cedo, mesmo antes de a criança adentar as salas de aula é de suma importância para construção de uma sociedade letrada. A escolha do tema não se deu por acaso, escolhi Literatura por acreditar que por meio dela podemos formar leitores assíduos. A pesquisa foi realizada numa escola pública de Educação Infantil situada no Distrito de Cariutaba, município de Farias Brito - CE e teve como objetivo conhecer as práticas de leitura trabalhadas pela escola. Foi conversado com $55 \%$ dos pais das crianças matriculadas na Educação Infantil (Creche e Pré-escola) e com todos os professores lotados no $1^{\circ}$ semestre do ano letivo em curso. Trata-se de um estudo de caso, para isso utilizei como metodologia a aplicação de questionários, entrevista e observação em sala de aula. $\mathrm{O}$ estudo nos coloca em destaque o grande desafio que a escola enfrenta que é difundir a leitura como algo primordial numa sociedade em que o nível de escolaridade dos pais é composta pela maioria por analfabetos funcionais.
\end{abstract}

Palavras Chave: Leitura - Escola - Educação Infantil

\section{La Literatura en la Educación Infantil: La Formación de Lectores en una Escuela de Educación Infantil en el Distrito de Cariutaba - Farias Brito - CE.}

Resumen: La lectura ha sido una cuestión que ha constituido una gran preocupación no sólo para la escuela, sino también para toda la sociedad. Trabajar la lectura desde temprano, incluso antes de que el niño adhiera a las aulas es de suma importancia para la construcción de una sociedad letrada. La elección del tema no se dio por casualidad, escogí Literatura por creer que por medio de ella podemos formar lectores asiduos. La investigación fue realizada en una escuela pública de Educación Infantil situada en el Distrito de Cariutaba, municipio de Farias Brito - CE y tuvo como objetivo conocer las prácticas de lectura trabajadas por la escuela. Fue conversado con el 55\% de los padres de los niños matriculados en la Educación Infantil (Guardería y Preescolar) y con todos los profesores llenados en el primer semestre del año escolar en curso. Se trata de un estudio de caso, para ello utilicé como metodología la aplicación de cuestionarios, entrevista y observación en el aula. El estudio nos pone de relieve el gran desafío que la escuela enfrenta que es difundir la lectura como algo primordial en una sociedad en que el nivel de escolaridad de los padres está compuesta por la mayoría por analfabetos funcionales.

Palabras Clave: Lectura - Escuela - Educación Infantil

\footnotetext{
${ }^{1}$ Graduação em Letras pela Universidade Regional do Cariri, Especialista em Língua Portuguesa e Arte-Educação pela Universidade Regiona do Cariri - URCA, Especialista em Gestão Escolar pela Universidade Federal do Ceará. Possui Curso Sequencial de formação especifica em Gestão em Esporte e Lazer pela Universidade Regional do Cariri. Contato: emanuel.mateus23@gmail.com.
}

76 Id on Line Rev. Mult. Psic. V.12, N. 42, p. 76-92, 2018 - ISSN 1981-1179
Edição eletrônica em http://idonline.emnuvens.com.br/id 


\section{Introdução}

A escolha para cursar Letras - Língua Portuguesa e suas respectivas Literaturas - não foi por acaso. A partir das leituras e estudos linguísticos percebi que era a faculdade que deveria seguir e assim fiz. No terceiro semestre escolhíamos qual habilitação seguir e não pensei duas vezes para eleger a Literatura Brasileira e Portuguesa e suas ramificações como minha formação acadêmica. Os estudos literários tanto as escolas (estilos) e a teoria da Literatura me fez perceber que o arcabouço teórico que temos nessa área do conhecimento é múltipla e transformadora.

Busquei ao longo desse percurso conhecer a fundo a parte literária e como aplica-la dentro das escolas em prol da formação de leitores. Nos últimos anos, notei nitidamente o encantamento das crianças nos momentos de leitura realizadas na Escola de Educação Infantil a qual sou voluntário no projeto de leitura e que tenho filhas matriculadas. A cada entonação e a cada gesto realizado nos momentos das leituras era perceptível a atenção dada pelas crianças, mesmo aquelas que ainda não tem o domínio da escrita. Percebi que essa é a etapa da Educação Básica que podemos trabalhar o gosto pela leitura e, foi através da Literatura Infantil que aprendi a me encantar cada vez mais pela leitura por prazer.

Portanto, esse trabalho busca em linhas gerais analisar o trabalho com a leitura realizado dentro das salas de aulas de uma escola localizada no Distrito de Cariutaba no município de Farias Brito - CE. Embasado em pesquisa bibliográfica e de campo ao longo dos meses do ano letivo de 2018.

Para tanto, dividi o corpus da pesquisa a saber: no primeiro momento irei fazer uma discussão sobre a literatura na escola, colocando em destaque um resumo histórico da Literatura Infantil nas escolas de Educação Infantil e, como os Referenciais Curriculares Nacionais para Educação Infantil (RCNEI) trata sobre o ensino de leitura nessa etapa. Posteriormente, farei uma análise da leitura na Educação Infantil, buscando demonstrar a prática de leitura no contexto dessa etapa educacional. Em outro momento, apresentarei a pesquisa de campo demonstrando como se é trabalhado a leitura na escola. Por fim, farei as considerações finais.

Segue adiante, algumas discussões que acredito ser pertinente para aqueles que escolheram a carreira de docência para sua vida. 
Segue adiante, algumas discussões que acredito ser pertinente para aqueles que escolheram a carreira de docente para suas vidas.

\section{A Literatura na Escola}

A escola é considerada como um espaço significativo para a formação de leitores. Assim como Kleiman, acredito que $a$ aprendizagem da criança na escola está fundamentada na leitura (2007, p.7). A prática literária está presente em todas as etapas da Educação Básica, sendo que em cada uma delas uma maneira lógica de se trabalhar com as obras literárias e com a prática de leitura.

Nesse ponto, busco discutir aspectos históricos da Literatura na Educação Infantil, bem como é tratado à questão da leitura nos documentos orientadores dessa etapa da educação.

\section{Breve histórico da literatura na Educação Infantil}

É sabido que a definição do que é literatura é algo difícil de se concretizar, pois, a arte literária tem um "leque" de definições. Portanto, usaremos nesse trabalho a definição de que a literatura é a arte que emprega como instrumento a palavra.

Além das definições da literatura temos ainda as variações literárias que direciona a um público alvo, tai como: literatura de cordel, literatura infantil entre outras. Neste corpus abordaremos somente a literatura infantil. Corroboro com o pensamento de Cagneti, quando ela diz que:

\footnotetext{
A Literatura infantil é, antes de tudo, literatura, ou melhor é arte: fenômeno de criatividade que representa o Mundo, o Homem, a Vida, através da palavra. Funde os sonhos e a vida prática; o imaginário e o real; os ideais e sua possível/impossível realização (CAGNETI, 1996, p. 7)
}

A partir da compreensão ampla dada sobre o que é Literatura infantil na visão da autora citada acima, percebemos o quão é importante o trabalho desse gênero literário nas escolas. 
Percorrendo a história do gênero em destaque, verifica-se que ela surge em meados do século XVIII com a ascensão da burguesia europeia. Conforme Cunha,

A história da literatura infantil tem relativamente poucos capítulos. Começa a delinear-se no início do século XVIII, quando a criança pelo que deveria passa a ser considerada um ser diferente do adulto, com necessidades e características próprias, pelo que deveria distanciar-se da vida dos mais velhos e receber uma educação especial, que a preparasse para vida adulta. (Cunha, 1999, p. 22)

Nessa época crianças da classe burguesa faziam uso da leitura como forma de ascensão social e formação humana, tinham acesso aos livros clássicos. É necessário saber que a prática literária não ficou resguardada somente aos burgueses, mas as crianças de classe inferiores praticavam a leitura e adquiria conhecimento através da oralidade e das histórias contadas pelas pessoas mais velhas.

É pertinente dizer que no início os textos voltados para o público infantil eram adaptações dos textos escritos para adultos e ou a conversão das histórias folclóricas em contos de fadas, isso tudo para que fosse adequado ao nível de apreensão do conhecimento linguístico e textual da criança.

Ler histórias para crianças, sempre, sempre... É poder sorrir, rir, gargalhar com as situações vividas pelas personagens, com a ideia do conto ou com o jeito de escrever dum autor e, então, poder ser um pouco cúmplice desse momento de humor, de brincadeira, de divertimento... E também suscitar o imaginário, é ter a curiosidade respondida em relação a tantas perguntas, é encontrar outras ideias para solucionar questões (ABRAMOVICH, 2005, p. 17)

É a partir do pensamento da autora Abramovich que se nota a relação existente entre a Literatura Infantil e a primeira etapa da Educação Básica. Tendo em vista os procedimentos metodológicos e pedagógicos desenvolvidos nas salas de aula da Educação Infantil estão envolta dessa ludicidade. 


\section{O Ensino de Leitura e os Referenciais Curriculares Nacionais para Educação Infantil}

A Educação brasileira é permeada por conquistas, transformações, reformulações e tentativas no intuito de oferecer uma política pública de qualidade. Assim as Leis que rege a educação no país vem ao longo dos anos passando por reformas constantes.

Novas e importantes conquistas foram conseguidas a partir da implantação da Lei de Diretrizes e Bases da Educação Nacional 9394/96, que trouxe uma reforma educacional dentre outras propostas para melhoria da qualidade da educação. Dentro dessa reforma citamos a inserção da Educação Infantil como primeira etapa da Educação Básica, tendo em vista que em versões anteriores essa etapa não era dado o seu respectivo valor.

A partir dessa valoração é possível encontrar textos que dão a fundamentação teórica a cada etapa de ensino, orientando para seleção de conteúdo, métodos e competências a serem desenvolvidas ao longo do processo educativo.

Nesse trabalho me deterei somente aos documentos norteadores da Educação Infantil. De acordo com Brasil (2013, p. 99):

Art. $9^{\circ}$ as práticas pedagógicas que compõem a proposta curricular da Educação Infantil devem ter como eixos norteadores as interações e a brincadeira, garantindo experiências que:

(...) IX - promovam o relacionamento e a interação da criança com as diversificadas manifestações de música, artes plásticas e gráficas, cinema, fotografia, dança, teatro, poesia e literatura; (...)

Com a formulação das etapas do ensino e a criação de diretrizes afim de alcançarem os objetivos desejados, surge ao longo de estudos referenciais curriculares que ajudarão de fato a fortalecer o ensino e aprendizagem.

No tocante a primeira etapa da educação básica, é formulado o Referencial Curricular Nacional para Educação Infantil (RCEIN). Dividido em três volumes, traz para os profissionais e comunidade escolar um conhecimento apurado para o trabalho com a criança em toda sua etapa de desenvolvimento. Aqui, farei referência ao volume três dos referenciais, intitulado como Conhecimento de Mundo, o documento traz propostas e conteúdos teóricos para o trabalho nas diversas séries do ensino infantil. O mesmo é dividido em eixos do conhecimento que são: Movimento; Música; Artes Visuais; Linguagem oral e escrita; Natureza e sociedade e 
Matemática. Nesse trabalho irei me deter somente ao eixo de Linguagem oral e escrita, tendo em vista que trabalha diretamente com a Língua. Segundo Brasil (1998, p. 117):

O trabalho com a linguagem se constitui um dos eixo básicos na educação infantil, dada sua importância para a formação do sujeito, para a interação com as outras pessoas, na orientação das ações das crianças, na construção de muitos conhecimentos e no desenvolvimento do pensamento.

A linguagem seja ela oral ou escrita é vista dentro do documento como eixos norteadores do conhecimento de mundo, pois sendo a linguagem de natureza transdisciplinar reguladora do meio social é capa de permitir o desenvolvimento das capacidades cognitivas dos alunos.

Pode-se notar que o trabalho pedagógico desenvolvido na Educação Infantil não é feito a "solta" como muitos acham e que nessa etapa o que importa é fazer com que as crianças brinquem. Alguns fragmentos expostos acima demonstra a fundamentação teórica para o trabalho com as crianças e que tem-se objetivos a serem alcançados ao longo do processo de escolarização.

Dentre os objetivos encontrados nos documentos e diretrizes para o ensino destaco dois que estão diretamente ligados com o nosso objeto de pesquisa. Um deles é que as crianças de 0 a 3 anos consigam interessar-se pela leitura de histórias; e o outro escutar textos lidos, apreciando a leitura feita pelo professor, para crianças de 4 a 6 anos (Brasil, 1998, p. 131).

Sobre a prática de leitura, Brasil (1998, p. 135) ressalta que:

A leitura pelo professor de textos escritos, em voz alta, em situações que permitem a atenção e a escuta das crianças, seja na sala, no parque debaixo de uma árvore, antes de dormir, numa atividade específica para tal fim etc., fornece às crianças um repertório rico em oralidade e em sua relação com a escrita.

É perceptível que a leitura e escrita estão intimamente interligadas e que o trabalho de uma fornece subsídios para o desenvolvimento da outra. No entanto, devemos ter em mente que o trabalho com a linguagem na Educação Infantil não busca a aquisição da língua padrão da norma culta, na verdade, ela busca desenvolver habilidades de leitura e escrita a serem desenvolvidas nas etapas posteriores da Educação Básica. 
Não é objetivo geral do ensino de leitura nessa etapa fazer com que o aluno sai da Educação Infantil sendo detentor do signo linguístico, busca como dito anteriormente que a criança desenvolva o gosto pela leitura. Assim como Cavalcante (1997, p. 27) acredito que,

\footnotetext{
Ler antes de saber ler é um convite à interpretação de sinais gráficos, a partir do conhecimento prévio do aluno a leitura convencional também é uma interpretação de sinais gráficos realizados a partir de nosso conhecimento anterior. Portanto, quando se pede que o aluno lei antes de saber fazê-lo convencionalmente, está-se na verdade convidando o aluno para ocupar o lugar de um leitor potencial.
}

Fica claro que o ensino de leitura na Educação Infantil deve acontecer antes mesmo da criança conhecer o signo linguístico na sua representação escrita. É importante lembrar que $a$ leitura não está restrita às letras impressas em uma página de papel. (MANGUEL Apud COSSON, 2007, p. 38).

Por tudo que foi exposto até o momento, vale salientar que, a prática de leitura deve ser inserida em todas as etapas da Educação Infantil - Creche (Crianças de 0 a 3 anos e 11 meses) e Pré-escola (Crianças de 4 a 5 anos e 11 meses), assim, o gosto pela leitura e o subsequente processo de alfabetização fluirá de forma mais prazerosa e rápida quando as crianças chegarem as etapas posteriores da Educação Básica (Ensino Fundamental e Médio).

\section{A leitura na Educação Infantil}

Educação Infantil período de iniciação escolar, fase de adaptação e primeira etapa da educação formal de um indivíduo. (...) tem como finalidade o desenvolvimento integral da criança de zero a cinco anos de idade em seus aspectos físicos, afetivo, intelectual, linguístico e social, complementando a ação da família e da comunidade (Lei n 9394/96, art. 29 apud Brasil, 2013, p. 83).

Sendo o primeiro contato da criança com a educação escolar, a interagir com outras linguagens e com outras pessoas, ela irá se desenvolver a partir dos estímulos dados pelos docentes. Seja qual for eixo a ser trabalhado, quando bem planejado terá êxito positivo em todo o processo. 
Por ser a fase inicial, acredito que a Educação Infantil é o primeiro passo para conquista e descoberta da leitura, já que, a educação é feita por processos e etapas complementares. É importante lembrar que, a criança que ainda não sabe ler convencionalmente pode fazê-lo por meio da escuta da leitura do professor, ainda que não possa decifrar todas e cada uma das palavras. Ouvir um texto já é uma forma de leitura. (BRASIL, 1998, p. 141).

Vale salientar que nas primeiras séries da Educação Infantil dificilmente o aluno será um leitor coeso e coerente de textos, mas, ele poderá ser um leitor assíduo se nessas séries forem estimulados a leitura pela escrita, pela imagem transformada em histórias orais pelos que eles enxergam na imagem.

\section{Deixa que eu conto - a contação de histórias: um dos caminhos para formação de leitores}

Ao longo desse trabalho foi mencionado que ao se trabalhar a leitura na Educação Infantil, não podemos pensar em se trabalhar a leitura numa perspectiva convencional do ensino de leitura. É importante lembrar que cabe ao professor no início do processo formativo o incentivo para o trabalho com a leitura, o desenvolvimento do gosto pela leitura seja ela oral ou escrita.

É um trabalho sistemático a ser desenvolvido dentro das salas de aula. Para o incentivo a prática e gosto da leitura, confio assim como Brasil (1998, p. 140) que a narrativa pode e deve ser a porta de entrada de toda criança para os mundos criados pela literatura. A criança aprende a narrar por meio de jogos de contar e de histórias.

Rodrigues (2005, p.4), deixa claro que,

A contação de histórias é atividade própria de incentivo à imaginação e o trânsito entre o fictício e o real. Ao preparar uma história a ser contada, tomamos a experiência de narrador e de cada personagem como nossa e ampliamos nossa experiência vivencial por meio da narrativa do autor. Os fatos, as cenas e os contextos são do plano do imaginário, mas os sentimentos e as emoções transcendem a ficção e se materializam na vida real.

É por esse meio de contar e recontar que a criança tende a desenvolver o hábito de manusear, folhear e posteriormente tornar-se um leitor assíduo. Vale lembrar que nesse jogo de 
contar devemos deixar a criança participar ativamente do processo, mesmo que sua narração sai descompassada e incoerente.

Ainda sobre a importância da contação de história para formação do leitor Torres; Tettamanzy (2008, p. 1) diz que,

\begin{abstract}
A história contada através da oralidade permite a interação entre contador e ouvintes, já que o corpo e a voz propiciam vivências comunitárias, perdidas na aceleração da vida moderna. (...) O principal objetivo de contar uma história é divertir, estimulando a imaginação, mas uma história bem contada pode aumentar o interesse pela aula ou permitir a auto-identificação, favorecendo a compreensão de situações desagradáveis e ajudando a resolver conflitos.
\end{abstract}

Vale lembrar que não é somente o fato de narrar histórias que atrai a atenção dos ouvintes. A narração deve está envolta a elementos atrativo, encantador, permeados por performances do contador. Torres; Tettamanzy (2008, p. 5) diz que contar histórias é a arte performática, em que se tenta transmitir os contos pelos meios nos quais surgiram, ou seja, através da voz, corpo e gesto. Assim, contar histórias não é somente verbalizar a palavra escrita sem a presença do movimento corporal. Faz-se necessário a "encarnação" das personagens para que a história tenha sentido para a criança. Zumthor apud Torres; Tettamanzy (2008, p. 5) afirma que, a performance designa um ato de comunicação como tal, refere-se a um momento tomado como presente. A palavra significa a presença concreta de participantes nesse ato de maneira imediata.

Acredito que é nesse "deixa que eu conto" em que se desenvolve o gosto pela leitura e desenvolve a oralidade. Pelo exposto acima, nota-se que é imprescindível a presença das contações de histórias nas salas de Educação Infantil para formação de futuros leitores.

\title{
A prática de leitura na Educação Infantil
}

Os desafios impostos aos professores que trabalham com a Educação Infantil têm sido alvo de inúmeras pesquisas e estão no cerne da atual agenda dos estudos da linguagem.

Há algumas décadas, a prática de leitura na escola alicerçava-se em atividades nas quais se recorria apenas à linguagem oral e de forma esporádica a escrita, ou seja o ensino de 
forma mecânica de repetição e escrita das letras. O aluno era condicionado a memorizar as letras das palavras, por exemplo, no processo de conhecimento das letras dizia-se que a letra "A" era da palavra "Avião" e a criança sempre que ouvia a letra "A" correlacionava a palavra aprendida em sala de aula.

Perpassando por várias modificações o ensino e aquisição da linguagem nas salas das escolas infantis deixa de ser a memorização de palavras e letras e passa a ser um processo de interação entre aluno-professor, aluno-aluno, aluno-texto. Passaram a utilizar o texto nas suas mais variadas vertentes e o trabalho com a leitura passou a envolver elementos tais como: oralidade, imagem, cores, código alfabético escrito.

Tais reformulações passaram a exigir um novo ensino de leitura, no caso dos alunos e professores a aquisição e o desenvolvimento de outras habilidades de leitura e escrita, dependendo das modalidades utilizadas, ampliando a noção de trabalho literário com múltiplos trabalhos com a leitura.

Com as novas exigências, foram sendo colocadas em salas de aulas práticas inovadoras de ensino de leitura, divido em momentos, tais como: hora de leitura contada pelo professor; hora da leitura feita pelo aluno - mesmo este não tendo domínio da língua escrita -; hora da leitura realizada pelos pais, etc. Os documentos norteadores da educação, dentre eles as Diretrizes Curriculares deixa evidente algumas considerações acerca da linguagem na Educação Infantil.

De acordo com Brasil (2013, p. 94),

É necessário considerar que as linguagens se inter-relacionam: por exemplo, nas brincadeiras cantadas a criança explora as possibilidades expressivas de seus movimentos ao mesmo tempo em que brinca com as palavras e imita certos personagens.

Complementa ainda que dentre os bens culturais que a criança têm o direito a ter acesso está a linguagem verbal, que inclui a linguagem oral e a escrita, instrumentos básicos de expressão de ideias, sentimentos e imaginação (Brasil,2013, p. 94).

Esse direito pode ser garantido através de práticas que envolvem as mais diferentes situações de comunicação, que pode ir desde uma conversa informal até uma situação formal da educação escolar. 
Vale salientar que o novo contexto em que a educação se situa passa a exigir uma corresponsabilidade de todos para o aprimoramento da criança, ou seja, todos os segmentos devem se envolver para o gosto e aquisição da leitura, onde o trabalho com a leitura deixe de ser somente da escola ou da família, mas que seja de ambas instituições.

A leitura não pode ficar resguardada somente a escola. O manuseio do livro deve ocorrer em todos os locais em que a criança esteja. Devemos propiciar as crianças o contato direto com o livro, mesmo que ela venha rabisca-lo e/ou rasgá-lo. Os livros pertencentes ao acervo da escola deve ser emprestados para que os alunos levem para casa. Sobre isso Brasil (1998, p. 125) nos diz que:

(...) Deixar as crianças levarem um livro para casa, para ser lido junto com seus familiares, é um fato que deve ser considerado. As crianças, desde muito pequenas, podem construir uma relação prazerosa com a leitura. Compartilhar essas descobertas com seus familiares é um fator positivo nas aprendizagens das crianças, dando um sentido mais amplo para a leitura.

\section{Formando leitores: a leitura e a prática de leitura numa Escola de Educação Infantil do Município de Farias Brito - CE.}

A questão literária é trabalhada em todas as etapas da Educação Básica, já que, é por meio da leitura que o indivíduo consegue internalizar os conhecimentos adquiridos ao longo dos anos. Sejam aqueles ensinados pela escola ou pela família, pois, a leitura não está diretamente ligada somente a codificação do signo linguístico, mas a toda interpretação que podemos fazer do contexto o qual estamos inseridos.

É sabido ainda que o trabalho com a leitura requer dos educadores um esforço extra, pois, trabalhar com a leitura não é tarefa fácil.

\section{Metodologia}

Buscando atingir o objetivo da pesquisa que foi analisar e comparar os métodos adotados pela Escola de Educação Infantil localizada no Distrito de Cariutaba, município de Farias Brito - CE no trabalho para se trabalhar a leitura a partir da Literatura Infantil, fez-se 
uma revisão bibliográfica, para construção da fundamentação teórica. Realizei pesquisa com professores, coordenação pedagógica e pais, além, de observações em sala de aula ao longo dos meses de construção desse trabalho. Com base nas reflexões de alguns autores e na sondagem dentro da escola, fez-se um estudo comparativo das diferentes formas de lidar com a leitura na escola; e a partir dos dados obtidos, foi possível reunir estratégias que podem colaborar para a qualidade da educação.

Posso dizer ainda que, tanto os professores como os pais não hesitaram em responder os questionamentos que forma aplicados, o que ajudou, a realização e consolidação dos dados da pesquisa.

\section{Análise da pesquisa}

A questão da leitura vem sendo tratada em todas as etapas da Educação Básica, como primordial para o sucesso escolar. A formação de leitores e a formação de professores para o trabalho com a leitura vem sendo detalhado e discutido em encontros educativos seja na rede de ensino fundamental e médio, seja nos centros acadêmicos de Ensino Superior.

$\mathrm{Na}$ Educação Infantil, não é diferente das outras etapas da educação, com o objetivo de fomentar a leitura desde cedo núcleo gestor, professores e pais vem trabalhando de forma significativa para que a leitura torne-se de fato um hábito.

Quando visitei a escola, campo de pesquisa, conversei de forma informal com os profissionais que trabalham naquele estabelecimento. Inicialmente perguntei aos professores o que de fato tem se trabalhado dentro das salas de aula para formação de leitores.

\footnotetext{
Prender a atenção dos alunos para a leitura é algo que exige de nós um esforço ímpar. Lutamos contra a inquietude e principalmente, conta a energia que os alunos tem. Procuro me fantasiar para contar as histórias buscando prender a sua atenção. Todos os dias existe o momento da história, faço rodas para que eles fiquem a vontade, entrego livros para que eles fiquem folheando. Procuro fazer de tudo um pouco. (PROFESSORA A, 2018)

Coloco eles para contar histórias de todos os tipos. Cada aluno tem até 10 minutos para contar uma história. Após isso, eu começo contar as histórias dos livros, observei que tem dado certo e que eles procuram os livros depois, mesmo que seja para fazer a leitura das gravuras. (PROFESSORA B, 2018)
} 
Pelos relatos das professoras observo que a prática de leitura é trabalhada dentro das salas de aula. Sabemos que não basta somente a escola fazer a sua parte na difusão da leitura e que se a família não for trabalhada para vivenciar a leitura no lar dificilmente a criança será habituada para vivenciá-la. Sobre isso perguntei a coordenadora pedagógica o que a escola tem feito para fomentar a leitura dentro do ceio familiar.

\begin{abstract}
A Escola tem feito um trabalho de sensibilização para que a leitura seja de fato vivenciada em todos os ambientes da criança. Confesso que é um trabalho difícil, mas, de forma lenta está dando certo. Para isso, elaboramos um projeto de leitura que a cada semana uma mãe tem a tarefa de contar a história para seu filho e no dia seguinte vir até a sala dele e contar a história para seus colegas, juntamente com a criança. Digo ainda que é lenta a participação da família, mas, observamos um aumento significativo da participação. (COORDENADORA, 2018)
\end{abstract}

E nos encontros pedagógicos, nos momentos de planejamento como é tratada a questão literária na Educação Infantil.

Quando realizamos os encontros pedagógicos na escola, buscamos trabalhar de fato a
questão da leitura na Educação Infantil. Sempre faço uma busca na internet, em livros
de formação de leitores buscando modelos para que seja adaptada a realidade de
nossos alunos. Elaboramos conjuntamente as nossas ações, lembrando que, sempre
em consonância com o Referencial Nacional para Educação Infantil e os documentos
norteadores elaborados pela Secretaria Municipal de Educação.
(COORDENADORA, 2018)

Brasil (2013, p. 86) nos diz que:

A criança, centro do planejamento curricular, é sujeito histórico e de direitos que se desenvolve nas interações, relações e práticas cotidianas a ela disponibilizadas e por elas estabelecidas com adultos e crianças de diferentes idades nos grupos e contextos culturais nos quais se insere. (...)

A respeito disso indaguei a coordenação pedagógica e as professoras sobre os critérios levados em consideração no momento da construção do plano pedagógico e de aula da escola.

Em primeiro lugar levamos em consideração o aluno, enquanto sujeito da sociedade, enquanto diferente de todos os outros e com suas particularidades. Quando elaboro o plano de aula, verifico se o que foi trabalhado no dia anterior foi satisfatório para criança se elas pelo menos demonstraram através de olhares e risos que estão gostando da aula. Isso pode ser verificado nas conversas com as mães sobre os relatos ditos em casa já que, na Educação Infantil não temos uma "prova" escrita ou de outra forma para avaliarmos o que a criança aprendeu de fato. (PROFESSORA A, 2018) 
Eu busco fazer com que os meus alunos se sintam bem, se sintam criança de verdade. Se a atividade é de pintura, me lambuzo com eles, se é de contação de história me transformo em todos os personagens possíveis. De bruxa a Mamãe Noel, faço de tudo para que eles gostem de mim. (risos) (PROFESSORA B, 2018)

A escola procura adequar-se à realidade em que está inserida. A cultura local é a primeira levada em conta quando estamos elaborando o nosso plano pedagógico. Temos uma sociedade diversificada e essa diversificação é respeitada em todos os momentos de planejamento, execução e avaliação de nossas atividades. O que queremos de fato com isso, é formar as nossas crianças para as séries futuras e para a vida. (COORDENADORA, 2018)

Acredito que o progresso estudantil somente acontece se a leitura for de fato um elemento que faz parte da vida do educando. Sobre isso perguntei qual a importância que os pais e professores da referida instituição de ensino dão a leitura.

Não tenho conhecimento das letras como gostaria. Leio pouco, as letras muitas das vezes se embaralha na minha cabeça e a palavra não sai. É por esse motivo que incentivo minha filha a aprender as letras, a ler e escrever. Não quero que ela seja mais uma de eu na vida, sem estudo suficiente para lhes dar uma vida melhor. (FRANCISCA (Mãe de uma aluna do Jardim III), 2018)

Leio sempre que posso na frente de meus filhos. Quero que eles me vejam com livros nas mãos para que eles se incentivem pela leitura. Acredito que sem leitura não somos nada. (JOANA (mãe de uma aluno do Maternal), 2018)

A leitura é a porta de entrada para o mundo. Não basta somente enxergar, temos que ter uma visão ampla em todos os sentidos. A decodificação dos signos linguísticos e a compreensão destes são de suma importância para o sucesso na vida. (PROFESSORA A, 2018)

É notável que nos diferentes segmentos que compõe a escola pesquisada a leitura é colocada como algo essencial para a vida em sociedade. Ainda sobre a prática de leitura exercida dentro da escola, perguntei a coordenação pedagógica e aos professores quais atividades eram usadas para fazer com que alunos tivessem interesse pela leitura, além das rodas de contação de histórias.

Além da "hora do conto" trabalhamos muito com formação de textos com gravuras, ou seja, escrevemos uma história a partir das gravuras recortadas por eles. Seria uma leitura visual oralizada das imagens colhidas. (PROFESSORA A, 2018)

Peço sempre que possível, os pais mesmo não sendo dia de o projeto vir à sala de aula para contar uma história. Quando a fundação Itaú abre as inscrições para doação de livros, sempre cadastro os pais de meus alunos para que eles possam ter livros em casa. (PROFESSORA B, 2018)

Nas reuniões de pais sempre colocamos em pauta a questão da leitura. Falamos sempre a importância desta para o sucesso das crianças na sociedade e na escola em séries futuras. Buscamos envolver os pais em todos os projetos e programas que fomente a 
leitura. Uma atividade que considero destaque além da maleta da leitura é "Pai leitor, filho leitor" em que uma vez no mês trazemos alguns pais para assistir aula com os filhos e trabalhamos a leitura. (COORDENADORA, 2018)

Pelas respostas colhidas pude perceber que a leitura tem um destaque especial nas ações trabalhadas dentro da escola pesquisada. Observei ainda que, a prática de leitura é vista como uma função social, portanto, sendo um dos objetivos a serem alcançados pelos profissionais que fazem aquela instituição.

\section{Considerações Finais}

Com o tempo e as experiências vividas durante a pesquisa, aprendi que uma investigação exige tempo e profundidade pra adentrar o processo que ela própria desencadeia. A procura de autores, de textos, de livros e de informações que pudesse me situar diante dos intentos; os entendimentos das próprias incertezas, na tentativa de conseguir definir os objetivos; a maturação para que as aprendizagens desenvolvidas pudessem ser relevantes ao que propomos, sem deixar de considerar o muito por aprender, tudo isso constituiu um tempo especial.

O objetivo maior nessa pesquisa foi o de conhecer a prática de leitura na Educação Infantil, para compreender o lugar que ocupou a leitura na vida dessas crianças e sua família. Pelas conversas e respostas que foram apresentadas, percebi que todos os envolvidos vivenciaram experiências deficitárias em relação à leitura. Não lhes foi possível, como ainda não parece ser no presente, desenvolver atividades voltadas para a leitura que envolva todos de forma eficaz.

Do exposto por cada uma das pessoas envolvidas, ficou evidente que consideram a leitura algo fundamental para o desenvolvimento da crianças e sua inserção no meio social, porém, em casa algumas delas não tem o hábito de verem os pais lendo, acredito que seja por questões culturais que isso ocorra, o que dificulta o trabalho da escola.

Como não pretendo simplesmente classificar o grau de leitura das crianças e também da comunidade escolar, mas sim conhecer os tipos de leituras realizadas e por que o fazem, entendo que a leitura na comunidade feita de forma esporádica pode ser decorrente da falta de condições financeiras para desenvolver outras práticas, fruitivas, por exemplo. A julgar a 
profissão e a situação econômica que vivem, fica fácil de entender o porquê de não aparecerem manifestações de leitura.

Se levarmos em consideração que a escola se utiliza de métodos e modelos de ensino para o desenvolvimento de suas ações, sobretudo, no início de cada etapa da escolaridade, perceberemos a importância desses para o processo educativo.É comum que se manifestem nas suas formas de ensinar a leitura, marcas das estratégias metodológicas que foram observadas em outras instituições de ensino e, que foram ensinadas durante a sua formação docente. As atividades experimentadas na escola e que foram concebidas como positivas, tem um grau de significação tanto dentro quanto fora da escola, isso posso comprovar quando nos remetemos as respostas dadas pelos pais dos alunos matriculado nesta instituição de ensino.

Posso definir que a escola desenvolve suas atividades de leitura de forma ativa e constante, adequadas aos seus afazeres cotidianos e ligados a comunidade escolar. Não ouso considerar a comunidade como toda não-leitora, pois entendo que as suas histórias não fortaleceram a prática de leitura como uma atividade agradável. Ao contrário, diversas pessoas que fazem parte da comunidade não tiveram acesso à educação escolar quando crianças, muitos deles, proibidos de ingressar na escola pela ignorância dos pais, por não acreditarem na educação como meio de transformação social. Era cultura antigamente eles pensarem que os estudos não era para os pobres.

Também não ouso descartar a possibilidade que essas pessoas tem de repensar as suas certezas sobre a leitura, pois, ao reconhecerem a importância da leitura, deveriam tê-la de forma mais presente em seu dia a dia.

Defendo que uma criança que tem contato frequente com livros ou materiais de leitura tem um conhecimento bem maior que os não-leitores. Espero que não consigam somente reconhecer o valor da leitura para o desenvolvimento intelectual, mas e sobretudo, que aprendam estratégias que ampliem as habilidades de compreensão e interpretação de textos.

Foi nesse exercício de pensar e repensar, fazer e refazer que finalizo o trabalho. Inconcluso sim, mas com um pouco mais de experiência, de saberes e de leituras. Dentre as idas e vindas, paradas e recomeços, penso ter "concluído" o estudo a que me propus. É valido considerar que a particularidade de cada resposta representa parte da vida da comunidade do Distrito de Cariutaba que se junta a tantas outras histórias, mostrando em seu conjunto um tempo em que a leitura perpassam por várias modificações e que conhecê-la faz-se necessário para vida em sociedade. 


\section{Referências}

BRASIL. Ministério da Educação e do Desporto. Secretaria de Educação Fundamental. Referencial curricular nacional para a educação infantil. Brasília: MEC/SEF, 1998. (Volume 3 Conhecimento de Mundo)

BRASIL. Ministério da Educação. Diretrizes Curriculares Nacionais Gerais da Educação Básica. Brasília: MEC, SEB, DICEI, 2013.

CAGNETI, Sueli de Souza. Livro que te quero livre. Rio de Janeiro: Nórdica, 1996.

COSSON, Rildo. Letramento literário: teoria e prática. $1^{\text {a }}$ ed. São Paulo: Contexto, 2007,

CUNHA, Maria Antonieta Antunes. Literatura Infantil: teoria e prática. 10 edição. São Paulo: Editora Ática, 1997.

FERREIRA, Norma Sandra de Almeida. Literatura Infanto-Juvenil: Arte ou pedagogia Moral? São Paulo: Cortez/Unimep, 1983.

KLEIMAN, Angela. Texto e leitor: Aspectos cognitivos da Leitura. $10^{\mathrm{a}}$ Edição, Campinas, SP: Pontes, 2007.

RODRIGUES, Edvânia Braz Teixeira. Cultura, arte e contação de histórias. Goiânia, 2005.

TORRES, Shirlei Milene; TETTAMANZY, Ana Lúcia Liberato. Contação de história: resgate da memória e estímulo à imaginação. Revista eletrônica de crítica e teoria de literaturas. Porto Alegre, v. 04, n. 01, 08 p. jan/jun. 2008. Disponível em http://seer.ufrgs.br/NauLiteraria/article/view/5844/3448. Acesso em 10 de março de 2018.

\section{Como citar este artigo (Formato ABNT):}

SILVA, Emanuel Mateus da. A Literatura na Educação Infantil: a Formação de Leitores em uma Escola de Educação Infantil no Distrito de Cariutaba - Farias Brito - CE. Id on Line Rev.Mult. Psic., 2018, vol.12, n.42, p. 76-92. ISSN: 1981-1179.

Recebido: 29/07/2018.

Aceito: 21/08/2018 